\title{
A aprendizagem de genética à luz da Teoria Fundamentada: um ensaio preliminar
}

\section{The learning of genetics in the light of Grounded Theory: a preliminary experiment}

\author{
Cirlande Cabral da Silva ${ }^{1}$. Josefina Barrera Kalhil ${ }^{2}$
}

\begin{abstract}
Resumo: O presente trabalho versa sobre as dificuldades que os alunos do Curso de Licenciatura em Ciências Biológicas do Instituto Federal do Amazonas enfrentam quando estudam a disciplina Genética. Diante desse panorama, fizemos um ensaio preliminar para elaborar uma Teoria Substantiva que explicasse o motivo pelo qual ocorria tal fenômeno. Diante disso, seguimos os três passos recomendados pela Teoria Fundamentada: (1) a codificação aberta; (2) a codificação axial e (3) a codificação seletiva. Os métodos da Teoria Fundamentada se basearam em diretrizes sistemáticas, ainda que flexíveis, para coletar e analisar os dados visando à construção de teorias. Portanto, para esse estudo, elaboramos a seguinte Teoria Substantiva: a dificuldade de compreensão dos assuntos de Genética leva o aluno a uma interpretação incompleta dos fatos (fenômenos) em decorrência de uma percepção esporádica, não desenvolvendo assim atitudes reflexivas para o devido entendimento (entende, mas não interpreta) dos assuntos relacionados à Genética.
\end{abstract}

Palavras-chave: Ensino superior. Ensino de biologia. Genética. Teoria fundamentada.

\begin{abstract}
This paper talks about the difficulties that students of Biological Sciences Degree Course of Amazonas Federal Institute face when studying genetics. Against this background, we did a preliminary experiment to establish a Substantive Theory to explain why this phenomenon occurred. Therefore, we follow the three steps recommended by the Grounded Theory: 1) open coding; 2) the axial coding and 3) the selective coding. The methods of Grounded Theory is based on systematic guidelines, although flexible, to collect and analyze data in order to build theories. Therefore, for this study, we developed the following Substantive Theory: "The difficulty in understanding genetics leads the student to an incomplete interpretation of the facts (phenomena) as a result of a sporadic perception, and thus not developing reflective attitudes for a proper understanding (understanding but not interpretation) of the issues relating to Genetics."
\end{abstract}

Keywords: Higher education. Biology teaching. Genetics. Grounded Theory.

\footnotetext{
${ }^{1}$ Instituto Federal de Educação Ciência e Tecnologia do Amazonas (IFAM), Departamento de Ensino Superior, Manaus, AM, Brasil. E-mail: <cirlandecabral@gmail.com>.

${ }^{2}$ Universidade do Estado do Amazonas (UEA), Escola Normal Superior, Manaus, AM, Brasil.
} 


\section{Introdução}

O presente trabalho é um recorte de uma investigação da tese intitulada: Análise sistemática do processo ensino aprendizagem de genética à luz da teoria fundamentada, defendida no ano de 2014 pelo primeiro autor. Ele versa sobre as dificuldades que os alunos do Curso de Licenciatura em Ciências Biológicas do Instituto Federal do Amazonas (IFAM) apresentam quando entram em contato pela primeira vez com os assuntos relacionados à disciplina Genética.

Essa dificuldade ficou evidente ao longo de alguns anos de Magistério no Ensino Superior, especificamente ao início de todo o ano letivo, pois sempre nos angustiamos ao ministrar tal disciplina. Durante esse período, verificamos que a grande maioria dos alunos do curso em questão não consegue relacionar, interpretar, analisar, discutir e recriar o conhecimento que é aprendido em sala de aula. Essa condição arrastava-se continuamente por vários e longos anos, com um nível de repetência e reprovação cada vez mais crescente.

Constatamos, consultando o Q- Acadêmico ${ }^{3}$, que de todas as disciplinas oferecidas no Curso de Licenciaturas em Ciências Biológicas daquele Instituto, aquela com maior nível de reprovação é a Genética.

Não sabemos exatamente o porquê de tal dificuldade. Talvez seja por esta disciplina apresentar um grau de raciocínio complexo exigindo do aluno um aporte teórico mais elevado, ou quem sabe, pelos alunos não apresentarem o que Ausubel chama de subsunçores ou "pontos de ancoragem" para que o conhecimento de Genética se torne realmente significativo, ou mais ainda, pela falta de uma metodologia adequada que facilite o processo ensino aprendizagem da disciplina em questão.

Várias pesquisas já foram realizadas com o objetivo de levantar e/ou analisar os conhecimentos e a compreensão que jovens estudantes têm sobre Genética (WOOD-ROBINSON; LEWIS; LEACH, 2000; WOOD-ROBINSON et al., 1998, entre outros). Os resultados dessas pesquisas foram preocupantes, pois revelaram que nem mesmo os conceitos básicos de Genética são compreendidos pelos estudantes ao final dos anos de escolaridade obrigatória.

Diante disso, propomos elaborar uma Teoria (Substantiva) que explique como ocorre o processo de aprendizagem de genética pelos alunos do Curso de Licenciatura em Ciências Biológicas do Instituto Federal do Amazonas (IFAM). Para tanto, faremos um ensaio preliminar tendo como pressuposto epistemológico a Teoria Fundamentada (GLASER; STRAUSS, 1967).

\section{Estudos preliminares realizados sobre o ensino de Genética}

Nos últimos cinquenta anos, a Genética tem se destacado como uma das áreas da Biologia que mais tem apresentado mudanças tanto nos aspectos conceituais como tecnológicos, sendo considerada a mais básica de todas as disciplinas dessa área, bem como o campo fundamental da Biologia, pelo seu caráter unificador e que integra todos os conceitos e informações biológicas (FRANCISCO, 2005). Dentre os diversos conteúdos de Biologia, a Genética é aquela disciplina que pode interferir diretamente na forma de participação na sociedade, colaborando

\footnotetext{
${ }^{3}$ Software responsável por todas as atividades didático-pedagógicas do IFAM. 
na formação de um sujeito social mais crítico, autônomo e comprometido com sua cidadania. Isto porque para entender o avanço das inovações científicas e tecnológicas é necessário certo grau de alfabetização científica, que estabeleça um compromisso com a cidadania e permita a participação ativa do indivíduo na sociedade (WOOD-ROBINSON et al., 1998).

Há setenta anos, por exemplo, não se conhecia que o Ácido Desoxirribonucleico (DNA) é o material genético que controla a síntese de proteínas. Para a proposta de Watson e Crick (os descobridores da estrutura da dupla hélice de DNA), faltavam, aproximadamente, 20 anos. Quem, naquela época, podia prever o desenvolvimento da nossa compreensão sobre o papel do DNA? Ou até mesmo, quem poderia estimar o desenvolvimento da Tecnologia do DNA Recombinante (Engenharia Genética)?

Segundo Bugallo Rodríguez (1995), na década de 1970 os estudos que abordam as crenças dos estudantes sobre temas de Genética são raros. O mesmo autor mostra em seu trabalho que no começo dos anos 1980 foram elaborados dois estudos de grande interesse para a didática da Genética: um que visava mostrar quais os conteúdos de Biologia são mais difíceis de aprender, e outro analisava quais eram os conteúdos considerados mais importantes e difíceis pelos professores de Ciências do ensino secundário. Os estudos existentes apontam a Genética como o conteúdo que aparecia nos primeiros lugares de importância e dificuldade, citando ainda: mitose-meiose, genética mendeliana e teoria cromossômica.

Desde a década de 1990 estudos de expressão internacional, como os trabalhos de Bahar, Johnstone e Hansell (1999), Banet e Ayuso (1995), Bugallo Rodríguez (1995), Stewart (1982) e, progressivamente, inúmeros outros trabalhos indicam que ensinar Genética é considerado muito importante e também muito difícil. Investigações subsequentes, inclusive as provindas da produção nacional, têm apontado para a importância do tema e para as dificuldades enfrentadas no ensino.

Ometto-Nascimento et al. (2001) constataram que nos últimos anos os avanços apresentados na área da Genética, já citados por vários autores, trouxeram grande volume de novas informações e que até a década de 1980 alguns conhecimentos como Engenharia Genética e Biologia Molecular eram limitados apenas ao meio acadêmico e que a partir dos anos 1990 passaram a ser frequentes nos meios de comunicação. Turcinelli et al. (2001), dizem que há evidências de uma crescente preocupação da mídia e da academia em abordar o conhecimento científico de maneira acessível e precisa, uma vez que os próprios pesquisadores se apresentam como redatores. Apesar do aumento do conhecimento científico, no que diz respeito aos conteúdos de Genética presentes nos livros didáticos, os mesmos permanecem inalterados, sendo que o que aumentou foram os recursos visuais e a inclusão de exercícios de vestibulares (OMETTO-NASCIMENTO et al., 2001).

Assim, percebemos que o ensino de Genética tem sido um dos tópicos mais investigados pelos pesquisadores que se dedicam ao ensino de Biologia devido a uma variedade de fatores, que se estendem da relevância social e econômica, com todas as implicações tecnológicas, sociais e éticas envolvidas, à sua importância na estrutura conceitual das ciências biológicas (BANET; AYUSO, 2003; BUGALLO RODRÍGUEZ, 1995; WOOD-ROBINSON; LEWIS; LEACH, 2000). 


\section{A importância do ensino de Genética}

A expansão do conhecimento científico gerou para a disciplina de Biologia, principalmente na área de Genética, um constante desafio e uma grande responsabilidade, pois o domínio desses conhecimentos é necessário para a compreensão do mundo, dos limites e possibilidades da Ciência e do papel do homem na sociedade na qual está inserido. Valle (2009) afirma que a ciência e a tecnologia mudaram "a cara do mundo" alterando o espaço, o contexto, a paisagem e as relações humanas. Ainda, segundo Krasilchik (2004), o tratamento de novos temas exigirá do professor uma relação estreita com a comunidade, de forma que possam ser considerados assuntos relevantes que não alienam alunos, mas que, ao contrário, contribuam para a melhoria da qualidade de vida da sua comunidade.

As Orientações Curriculares para o Ensino de Biologia (PARANÁ, 2008) afirmam que as informações genéticas representam um ponto notável no desenvolvimento do saber e promovem enorme avanço tecnológico na Ciência, com a reabertura de debates sobre as implicações sociais, éticas e legais que existem e que ainda surgirão por efeitos das pesquisas nessa área (PARANÁ, 2008).

No entanto, o que se observa hoje nas escolas de Ensino Médio é que os conteúdos relacionados à Genética, apesar de sua relevância, têm sido abordados superficialmente. Isso ocorre tanto pela dificuldade encontrada pelos professores, pois se tratam de assuntos relativamente novos, os quais na maioria das vezes não foram abordados durante o seu período de formação acadêmica, quanto pelos alunos, por serem conteúdos abstratos, difíceis de serem compreendidos.

No programa de incentivo à formação continuada de professores do Ensino Médio, os proponentes Loreto e Sepel (2006, p. 8) justificam:

Como a inclusão de Biologia Molecular, Genética e Biotecnologia nos currículos do curso de graduação é muito recente, a formação da maioria dos professores atuando em sala de aula não é suficiente para atender de modo adequado à maioria das questões levantadas pelos alunos. Na maioria das vezes, o professor não tem segurança para ordenar e conduzir discussões sobre temas complexos e polêmicos como, por exemplo: cultivo de células tronco, clonagem terapêutica ou reprodutiva, alimentos transgênicos ou terapia gênica.

Dessa maneira, percebe-se que assuntos relacionados à Genética são cada vez mais constantes na vida das pessoas. Afinal, atualmente, é muito comum o consumo de vários alimentos transgênicos, bem como as discussões sobre terapia gênica, células-tronco, genomas e clonagem. Esses temas também estão presentes nas escolas, no ensino de Biologia, influenciando na formação de uma consciência mais crítica dos cidadãos. Todo esse corpo de conhecimento é fundamental, portanto, é necessário que a população possa entender o grande espectro de aplicações e implicações da Genética.

Os grandes avanços científicos que ocorreram recentemente na área de Biologia geraram um volume muito grande de novas informações e de conhecimentos mais complexos nesta área. Há algumas décadas, a Genética vem sendo alvo de interesse pelos diversos meios 
de comunicação. Este destaque pode ser explicado pela influência direta deste tema na vida das pessoas (XAVIER; FREIRE; MORAES, 2006). Dada a relevância da Genética para a sociedade moderna, torna-se imprescindível que o sistema educacional atenda às exigências decorrentes do estado atual do conhecimento científico e promova a alfabetização científica dos alunos.

No Ensino Médio, quando o indivíduo está prestes a concluir uma etapa consideravelmente relevante de sua vida na Educação Básica, é muito importante que haja uma construção do conhecimento de qualidade e, sobretudo, proporcionar uma fundamentação teórico-prática mais consistente. É nesse momento escolar do ensino que os alunos terão uma estruturação preparatória para prosseguir na convivência em sociedade, especialmente no que se refere à sequência dos estudos, de forma que o embasamento construído ao longo do processo de ensino possibilite o pleno aprendizado dos principais fundamentos de Genética, e, atualmente, pode-se incluir a Biologia Molecular, pelos discentes.

Griffiths (2001) afirma que dentre os conhecimentos produzidos pela comunidade científica, apresentam grande importância aqueles provenientes da área da Genética. Os conteúdos dessa área possuem posição de centralidade entre os demais conteúdos da Biologia. Sua importância pode ser justificada, pois os conhecimentos dessa área são essenciais para o estudo e para a compreensão da Biologia vegetal, animal ou microbiana. Além disso, como nenhuma outra disciplina, a Genética se encontra em uma posição central dentre os aspectos de interesse humano. Ela está presente na vida cotidiana, tornando-se impossível ignorar suas descobertas.

\section{A Teoria Fundamentada}

A Grounded theory, ou Teoria Fundamentada, foi iniciada por Barney Glaser e Anselm Strauss em 1967, sendo apontada como uma das formas mais puras de pesquisa qualitativa. Esta técnica evoluiu por aproximadamente 30 anos enquanto esses autores trabalharam juntos ou em outras parcerias para seu desenvolvimento e aprimoramento.

A Grounded theory é uma metodologia em que os dados são sistematicamente coletados e analisados (GOULDING, 2001). A definição concisa de teoria talvez não deixe clara a riqueza de detalhes do procedimento de trabalho e de resultado obtido com este tipo de pesquisa. É necessário esclarecer o que Glaser e Strauss (1967) entendiam por teorias. Em seus entendimentos, eles afirmam existirem dois tipos básicos de teorias: as formais e as substantivas. O primeiro tipo é composto do que os autores chamam as "grandes" teorias, conceituais e abrangentes, enquanto que o segundo tipo se refere a explicações para situações cotidianas sendo, portanto, mais simples e acessíveis. Para Glaser e Strauss (1967), o tipo de teoria a ser desenvolvido pela Teoria Fundamentada se enquadra no segundo tipo, ou seja, as teorias substantivas.

Segundo Hutchinson (1988), Glaser e Strauss (1967) acreditavam que a Teoria Fundamentada poderia ser usada para gerar teorias substantivas que, ao contrário das grandes teorias formais, explicariam melhor as áreas específicas da pesquisa empírica, já que essas teorias nasceriam diretamente de dados do mundo real. Para Goulding (2002), a Teoria Fundamentada é um método qualitativo tendo, portanto, muitas semelhanças com os demais métodos, tais como a Etnografia (estudo descritivo e interpretativo da realidade do grupo) e a Fenomenologia, ou seja, quando há uma forte ênfase na subjetividade da realidade construída pelos respondentes (HANNABUSS, 1996). Embora sua finalidade seja a construção de teorias, sua utilização não necessariamente precisa ficar restrita aos pesquisadores que têm esse objetivo de pesquisa. Para 
Strauss e Corbin (1998, p. 288, tradução nossa), “[...] o pesquisador pode usar alguns, mas não todos os procedimentos para satisfazer seus objetivos de pesquisa”. Portanto, a Teoria Fundamentada mostra-se como um poderoso mecanismo de investigação qualitativa, devido ao seu rigor metodológico e analítico durante o tratamento dos dados.

Pacheco (2010) afirma que foi feita uma análise no acervo do banco de teses e dissertações da Capes e foi constatado que até 2007 haviam sido publicados 97 trabalhos com essa metodologia, sendo $62,9 \%$ de dissertações e $37,1 \%$ de teses. Ressalta-se que muitos trabalhos utilizaram uma parte da metodologia e não focaram na construção de teorias.

Ainda, segundo o autor citado anteriormente, quanto aos cursos que mais utilizam essa metodologia, pode-se verificar que 29,9\% estão relacionados à área de Enfermagem, 21,6\% à Administração, 18,6\% à Psicologia, 5,2\%, à Comunicação, 4,1\% à Educação e 3,1\% à Saúde Pública. As outras áreas têm poucas publicações nesta área. Diante dos percentuais destacados, acreditamos que é muito importante que possamos utilizar, em nossas pesquisas educacionais, a Teoria Fundamentada, por dois motivos cruciais: (a) Ela oferece um alto grau de rigor analítico, levando o pesquisador a formular teorias substantivas para o fenômeno investigado à luz dos dados obtidos; (b) Ela surge como uma técnica rigorosa de análise de dados, revelando que em Ciências Humanas, Sociais e Educacionais, o pesquisador pode (e deve) buscar meios e instrumentos de análises que possam ajudá-lo a responder seu problema de pesquisa com o máximo de clareza possível.

Já em relação às universidades que possuem mais trabalhos nessa área, destacam-se a Pontifícia Universidade Católica (PUC) com 16,5\% e a Universidade de São Paulo (USP) com 15,5\%. A Universidade Federal de São Carlos (UFSC) possui seis trabalhos publicados, totalizando 6,2\% do total (PACHECO, 2010).

Um exemplo específico de pesquisa realizada sob o método da Teoria Fundamentada, no Brasil, é o trabalho de Bacellar (2005) que teve como foco, ou problema de pesquisa, a compreensão da perspectiva dos professores contribuindo para o ensino de marketing. A escolha do método se deveu à premissa e ao objetivo principal e original desse método: inexistência de teorias sobre o assunto, caráter interativo entre os sujeitos e contexto social e certo equilíbrio entre objetividade e sensibilidade no processo de análise. A coleta de dados durou um ano e a autora seguiu pela metodologia proposta por Corbin e Strauss (1990). Sem, contudo, trazer uma teoria emergente, o trabalho atingiu o nível de conceitos e suas propriedades. Pode-se dizer que os resultados são contributivos para o ensino, especialmente em marketing. A autora mostrou que o método é rico e aplicável no contexto em que foi definido.

Partington (2000) faz uma análise sobre o estudo do comportamento gerencial. Sua abordagem principal parte do pressuposto de que o comportamento é um resultado de acordo com o modelo S-O-R (stimulus, organism, response). Ele contrapõe a Teoria Fundamentada como método de estudo para entender o comportamento sob o modelo citado. Após uma descrição do método e debate, propõe um método S-O-R e Teoria Fundamentada (que define teoria de uma forma mais simplificada e utiliza os dados sem as mesmas premissas originais). Em suma, Partington (2000) estuda a Teoria Fundamentada e vê validade como método de trabalho qualitativo, mas propõe simplificação e customização de sua aplicação.

Parry (1998) analisou que a liderança é um processo de influência social, mudança e transformação. O estudo da liderança se deu por métodos quantitativos ao longo do tempo e necessitava de métodos qualitativos, dada a sua essência. O autor cita um trabalho realizado em 
três empresas de transporte na Inglaterra com utilização parcial da Teoria Fundamentada Ainda, segundo Parry (1998) foi possível ir além dos achados convencionais e focar temas intrínsecos à liderança como liderança informal e transformacional.

\section{Breve histórico da Teoria Fundamentada}

A Teoria Fundamentada foi desenvolvida originalmente por dois sociólogos, Barney Glaser e Anselm Strauss (GLASER, 1978, 1992; GLASER; STRAUSS, 1967; STRAUSS, 1987). Embora cada um deles viesse de uma tradição filosófica e de pesquisa diferentes, suas respectivas contribuições foram igualmente importantes.

Anselm Strauss formou-se na University of Chicago, que possui um longo histórico e uma forte tradição em pesquisa qualitativa. Durante seus estudos foi fortemente influenciado por textos interacionistas e pragmáticos. As contribuições de sua formação para o desenvolvimento deste método foram: (a) a necessidade de sair a campo para descobrir o que está realmente acontecendo; (b) a relevância da teoria, baseada em dados, para o desenvolvimento de uma teoria e como base para a ação social; (c) a complexidade e a variabilidade dos fenômenos e das ações humanas; (d) a crença de que as pessoas são atores que assumem um papel ativo para responder a situações problemáticas; (e) a percepção de que as pessoas agem com base em significados; (f) o entendimento de que o significado é definido e redefinido através da interação; (g) sensibilidade para a natureza evolutiva e reveladora dos fatos (processos); e (h) consistências das inter-relações entre condições (estrutura), ação (processo) e consequências (TAROZZI, 2011).

Já Barney Glaser veio de uma tradição sociológica muito diferente, mas com algumas características compartilhadas que, sem dúvida, permitiram aos dois homens trabalharem juntos. Ele formou-se na Columbia University e suas ideias sobre pesquisa tiveram influência de Paul Lazarsfeld, conhecido como um inovador dos métodos quantitativos. Posteriormente, quando fazia análise qualitativa, Glaser viu especialmente a necessidade de fazer comparações entre dados para identificar, desenvolver e relacionar conceitos.

A tradição da Columbia também enfatizou a pesquisa empírica, em conjunto com o desenvolvimento da teoria. As tradições tanto da universidade de Chicago como a de Columbia estavam voltadas para a produção de pesquisa que pudesse ser usada por públicos profissionais e leigos. Por essa razão, muito dos textos sobre teoria fundamentada que surgiram da colaboração Glaser/Strauss, incluindo a monografia original sobre a morte (GLASER; STRAUSS, 1965, 1968) eram dirigidos tanto ao público leigo como aos colegas de disciplina.

Após a ruptura entre Glaser e Strauss, o segundo, juntamente com sua assistente Juliet Corbin escreveram, em 1990, o livro intitulado Basics of qualitative research (CORBIN; STRAUSS, 1990). Embora grande parte da essência do método da teoria original tenha sido mantida neste livro, houve algumas diferenças. Elas não foram intencionais; simplesmente surgiram à medida que Strauss continuava a conduzir, a ensinar e a discutir metodologia de pesquisa com colegas e alunos. A metodologia e os procedimentos descritos neste livro refletem a técnica de Strauss para fazer pesquisa. A primeira edição do texto foi escrita para fornecer um conjunto de técnicas e diretrizes para pesquisadores iniciantes, tanto nos Estados Unidos como em outros países, que lutam com o método e com a questão de como analisar os dados. A intenção era ser um suplemento para outros textos de teoria, especialmente Qualitative analysis (STRAUSS, 1987), e não tomar o lugar deles. 


\section{Procedimentos metodológicos, coleta e análise dos dados}

Diante do exposto, percebemos, portanto, a dificuldade que temos em utilizar esse método em nossas pesquisas, já que o foco central da teoria fundamentada está em gerar, de forma indutiva, ideias teóricas novas ou hipóteses a partir dos dados, em vez de testar teorias específicas de antemão (pré-concebidas). Assim sendo, propõe-se, nesse trabalho, fazer uma análise preliminar (que chamaremos de "ensaio") utilizando uma entrevista que fizemos a um aluno do Curso de Licenciatura em Ciências Biológicas do Instituto Federal do Amazonas (IFAM). É importante destacar a importância dos ensaios preliminares, pois segundo Tarozzi (2011), os neófitos que utilizam pela primeira vez a análise através da Teoria Fundamentada apresentam grandes dificuldades.

Nesse trabalho, optamos pela entrevista semiestruturada, pois segundo Gaskell (2002) esta é essencialmente uma técnica, ou método, para estabelecer ou descobrir que existem perspectivas, ou pontos de vista sobre os fatos, além daqueles da pessoa que inicia a entrevista. Com isso, a entrevista oferece informação contextual de abrangência capaz de explicitar sua especificidade.

É importante destacar que esse ensaio preliminar foi feito para verificarmos o procedimento metodológico (baseado na Teoria Fundamentada) que deveríamos fazer para se chegar a uma teoria substantiva que respondesse ao nosso fenômeno investigado. Nesse caso, investigamos o seguinte problema científico ao questionar o aluno: "Quais as suas dificuldades na compreensão de assuntos de Genética?"

A partir dessa problemática iniciamos nosso "ensaio". Este ensaio foi de suma importância para o desenvolvimento da tese de doutoramento Análise sistemática do processo ensino aprendizagem de genética à luz da teoria fundamentada, defendida em 2014, pois nos forneceu possibilidade de entender como esse método funciona. Assim, nossas análises se desenvolveram com maior rigor analítico e um olhar mais apurado sobre os dados obtidos. Corbin e Strauss (1990) afirmam que o pesquisador ao trabalhar com a Teoria Fundamentada deve ter (ou desenvolver) uma capacidade crítica e um olhar intenso sobre os dados analisados.

O primeiro passo da análise foi fazer a codificação chamada aberta. A codificação aberta que utilizamos foi linha por linha (Figura 1). Esta codificação significa repassar o texto e darmos nomes ou codificar cada linha do texto, mesmo que as linhas possam não ser sentenças completas. A ideia inicial foi forçar nosso pensamento analítico e a aproximação aos dados. É interessante destacar que um dos riscos da codificação e de qualquer tipo de análise qualitativa é transmitir nossos próprios motivos, valores e preocupações para os códigos e esquemas analíticos produzidos. Se não tomarmos o devido cuidado, nossa análise pode refletir mais nosso próprio preconceito e concepções anteriores do que as visões de nossos entrevistados (GIBBS, 2009).

A codificação é a forma como definimos os dados em nossa análise. Ela envolve a identificação e o registro de uma ou mais passagens de um texto ou outros itens nos dados. Geralmente, várias passagens são identificadas e então relacionadas com um nome para a ideia, ou seja, o código propriamente dito. Sendo assim, todo o texto, entre outros elementos, que se refere à mesma coisa, ou exemplifica a mesma coisa, é codificado com o mesmo nome. A codificação é uma forma de indexar ou categorizar o texto para estabelecer uma estrutura de ideias temáticas em relação a ele. A codificação é, portanto, uma forma de organizar nosso pensamento sobre o texto. Charmaz (2009) afirma que é importante, ao codificar, usar elementos nos gerúndios, pois eles nos levam a ações e a processos. 
Acreditamos que um dos maiores desafios neste ensaio foi identificar partes do texto e estabelecer quais códigos eles representam de forma teórica e analítica, e não apenas descritiva. Para isso, foi necessário não só um "olhar intenso" e cuidadoso no texto produzido pelo entrevistado, assim como uma "leitura intensa" ao codificar.

Uma das vantagens da codificação linha por linha foi nos forçar a prestar atenção àquilo que o entrevistado estava realmente dizendo e gerar códigos que refletissem a experiência de mundo dele e não a nossa, ou então, alguma pressuposição teórica que possamos ter.

Por outro lado, a codificação linha por linha não quer dizer que devemos simplesmente aceitar as visões que eles têm do mundo. Portanto, devemos ser o mais analítico e teórico possível em nossa codificação, mesmo que isso signifique, às vezes, que nossas interpretações possam ser diferentes das interpretações de nossos participantes. Assim, a premissa básica é que a codificação deva permanecer fundamentada nos dados constantes da transcrição.

Consideremos o Quadro 1. Alguns dos códigos do referido quadro ainda são um tanto descritivos, mas refletem as ações do que o referido aluno está falando e como sente dificuldade para compreender assuntos de genética. Dessa forma, a codificação linha por linha é só uma maneira de começar os trabalhos e o próximo passo é desenvolver e refinar essa codificação.

Quadro 1. Codificação linha por linha feita ao entrevistado

\begin{tabular}{|c|c|c|}
\hline \multicolumn{3}{|c|}{$\begin{array}{l}\text { Pergunta ao entrevistado: } \\
\text { Qual a sua maior dificuldade na compreensão de conteúdos de genética? }\end{array}$} \\
\hline \multicolumn{2}{|r|}{ Entrevistado } & Códigos obtidos \\
\hline 1 & Minha dificuldade é de entender mesmo... de relacionar & Dificuldade de compreensão \\
\hline 2 & o nome com o que tá acontecendo durante, vamos supor, uma... & Ausência de estratégia mental \\
\hline 3 & replicação. & Fenômeno descrito \\
\hline 4 & Eu consigo visualizar isso..., né...mas..., na hora de colocar isso no & Percepção esporádica \\
\hline 5 & papel... eu tenho dificuldade nessa hora da abstração. & Limitações de entendimento \\
\hline 6 & Assim, eu não tenho dificuldade, eu consigo compreender de fato o & Facilidade na compreensão \\
\hline 7 & que... o que o professor... ta sendo ministrado em sala de aula. & Entendendo o conteúdo \\
\hline 8 & Assim, o que eu tenho a dificuldade mesmo... é de passar isso para o & $\begin{array}{l}\text { Apresentando limitações de } \\
\text { escrita }\end{array}$ \\
\hline 9 & papel... & Interpretação do fenômeno \\
\hline 10 & Eu consigo entender o que tá acontecendo, eu lendo... o professor & Conseguindo interpretar \\
\hline 11 & Explica e mas eu tenho assim... assim... eu tenho essa dificuldade de & Dificuldade de interpretar \\
\hline 12 & colocar no papel o que o professor falou... & $\begin{array}{l}\text { Não consegue descrever o } \\
\text { fenômeno }\end{array}$ \\
\hline 13 & O professor deu uma aula, vou colocar tudo aquilo que o professor & Dificuldade de escrita \\
\hline 14 & explicou...eu tenho essa dificuldade. & Dificuldade em escrever \\
\hline 15 & Eu não consigo abstrair... & Dificuldade de entendimento \\
\hline 16 & Como eu posso deixar isso mais claro... eh... é assim, a dificuldade & $\begin{array}{l}\text { Grande dificuldade de } \\
\text { interpretação }\end{array}$ \\
\hline
\end{tabular}


Quadro 1. continuação

\begin{tabular}{|l|l|l|}
\hline $\begin{array}{l}\text { Pergunta ao entrevistado: } \\
\text { Qual a sua maior dificuldade na compreensão de conteúdos de genética? }\end{array}$ \\
\hline \multicolumn{2}{|c|}{ Entrevistado } & \multicolumn{1}{|c|}{ Códigos obtidos } \\
\hline $\mathbf{1 7}$ & $\begin{array}{l}\text { Eh...eh... eh, vamos supor, é durante uma prova colocar aquilo o que } \\
\text { o }\end{array}$ & Dificuldade de escrita \\
\hline $\mathbf{1 8}$ & professor explicou na sala de aula... & Ausência de interpretação \\
\hline $\mathbf{1 9}$ & Eu não consigo! & Não consegue refletir \\
\hline $\mathbf{2 0}$ & Como eu posso dizer... & Apresentando dificuldade oral \\
\hline $\mathbf{2 1}$ & Eu entendo, o professor dá as questões, eu consigo ler, eu sei o que & Conseguindo interpretar \\
\hline $\mathbf{2 2}$ & ele tá pedindo.... sei da onde é o conceito... o que tem que ser & $\begin{array}{l}\text { Conseguindo refletir sobre o } \\
\text { assunto }\end{array}$ \\
\hline $\mathbf{2 3}$ & explicando, mas, focar... colocar no papel... eu sinto essa dificuldade. & $\begin{array}{l}\text { Não consegue descrever o } \\
\text { fenômeno }\end{array}$ \\
\hline $\mathbf{2 4}$ & Eu não consigo... & Não consegue refletir \\
\hline $\mathbf{2 5}$ & Eu inicio... desenvolvo, mas assim, é é aquilo, não me sai bem, & $\begin{array}{l}\text { Descrevendo parcialmente o } \\
\text { fenômeno }\end{array}$ \\
\hline $\mathbf{2 6}$ & porque eu não coloquei o que deveria. & $\begin{array}{l}\text { Interpretação incompleta do } \\
\text { fato }\end{array}$ \\
\hline
\end{tabular}

Fonte: Silva (2014).

Refinar os códigos tem duas finalidades: em primeiro lugar devemos revisitar o texto para ver se ele pode ser melhor codificado de outra maneira, por exemplo, podemos utilizar códigos diferentes para codificar passagens mais longas e verificar se há exemplos em outros lugares da mesma transcrição, ou, em outras, que precisem ser codificadas usando os novos códigos. Também representa uma oportunidade de tornar os códigos descritivos iniciais mais analíticos.

Entretanto, a codificação feita no Quadro 1, na sua grande maioria, é simplesmente descritiva. Assim, necessitamos nos afastar das descrições, principalmente com os termos dos entrevistados e passarmos para um nível mais categórico, analítico e teórico de codificação. Dessa maneira agrupamos os códigos obtidos em seis categorias, como mostra o Quadro 2. Nesse agrupamento omitimos códigos repetidos e esclarecemos os nomes de um ou dois. $\mathrm{O}$ que na verdade fizemos foi reunir códigos semelhantes.

É importante destacar que seguimos as recomendações de Gibbs (2009) que afirma que devido à grande quantidade de códigos gerados na primeira fase de análise, é interessante organizá-los hierarquicamente para melhor visualização. 
A aprendizagem de genética à luz da Teoria Fundamentada: ...

Quadro 2. Agrupamento dos códigos

\begin{tabular}{|l|l|}
\hline \multicolumn{1}{|c|}{ Domínio interpretativo } & \multicolumn{1}{c|}{ Entendimento do conteúdo } \\
\hline Fenômeno descrito & Ausência de estratégia mental \\
\hline Interpretação do fenômeno & Dificuldade de compreensão \\
\hline Interpretação incompleta do fato & Limitações de entendimento \\
\hline Descreve (entende) o fenômeno & Grande dificuldade de interpretação \\
\hline Descreve parcialmente o fato & Não consegue descrever o fenômeno \\
\hline \multicolumn{1}{|c|}{ Limitações (na escrita) } & Atitudes reflexivas \\
\hline Certas limitações de escrita & Percepção esporádica \\
\hline Dificuldade em escrever & Consegue refletir sobre o assunto \\
\hline \multicolumn{1}{|c|}{ Domínio de conteúdo } & Ausência de domínio oral \\
\hline Facilidade de compreensão & Apresenta dificuldade oral \\
\hline Entendimento do conteúdo & \\
\hline
\end{tabular}

Fonte: Silva (2014).

\section{Organizando os códigos obtidos em uma hierarquia}

Depois que agrupamos os códigos, estes foram organizados hierarquicamente. Os códigos que guardam semelhanças ou que se referem ao mesmo assunto foram reunidos sob o mesmo ramo da hierarquia. A organização dos códigos em uma hierarquia envolve pensar sobre que tipos de coisas estão sendo codificadas e quais perguntas estão sendo respondidas. Dessa maneira, os códigos foram agrupados em seis categorias, a saber: dificuldade de compreensão, causas de dificuldade (interpretação incompleta do fato), atitudes reflexivas (percepção esporádica; entende, mas não interpreta).

Segue relação hierárquica de categorias e sub-categorias.

Dificuldade de compreensão

Causas de dificuldade

Interpretação incompleta do fato

Atitudes reflexivas

- Percepção esporádica

Entende mas não interpreta 
Após o desdobramento da codificação aberta, passamos para o segundo tipo de codificação chamado de codificação axial. Essa codificação se fez necessária em função do grande volume de conceitos originados na fase anterior.

Portanto, nessa fase, os códigos foram reagrupados de novas maneiras, levando em consideração aqueles que apresentavam semelhanças entre si e que tivessem o mesmo significado. Dessa forma, cada vez mais nos afastamos dos códigos meramente interpretativos, em busca de códigos mais analíticos e teóricos possíveis. Isso nos revelou os primeiros códigos conceituais (analíticos). Na verdade, o que fizemos foi reorganizar os códigos, em nível maior de abstração. Assim, novas combinações foram novamente estabelecidas de modo a formar as subcategorias que, por sua vez, foram organizadas compondo categorias analíticas principais.

Cabe ressaltar que, mesmo uma categoria, mediante sucessivas leituras e análises, pode regredir a código conceitual ou preliminar, de acordo com a reflexão realizada pelo pesquisador.

Para a elaboração da Teoria Substantiva, Corbin e Strauss (1990) propõem um formato de narrativa da seguinte forma: (A) condições levam ao (B) fenômeno, que surge num (C) contexto que leva a (D) ações e depois a (E) consequências.

Nesse modelo, os elementos podem ser definidos da seguinte forma: o fenômeno é a ideia/evento/acontecimento central aos quais as ações e interações estão relacionadas; as condições causais são os elementos/situações que possibilitam o surgimento do fenômeno; o contexto é a especificidade que envolve o fenômeno e o que condiciona a ação/interação; as condiçôes intervenientes são constituídas pelo tempo, espaço, cultura, situação econômica e tecnológica, história, biografia pessoal, dentre outros; as estratégias de ação/interação são identificadas com o caráter processual (sequências, movimento, mudanças, dentre outros), com um propósito, uma finalidade, sendo importantes também as não ações; e as consequências devem ser consideradas como o resultado/resposta, positiva ou negativa.

A terceira etapa, chamada de codificação seletiva, consistiu em refinar e integrar, ainda mais, todas as categorias obtidas de modo que pudesse ser revelada uma categoria (central) que interconectasse e permeasse todas as demais, a qual daria origem à Teoria Substantiva. Nessa fase, todo o potencial de abstração foi empregado no âmbito teórico dos dados investigados/ codificados, fazendo emergir a Teoria Substantiva. Todas as categorias, portanto, foram abstraídas, analisadas, refletidas, sistematizadas e interconectadas.

Podemos dizer, portanto, que nessa fase o processo chegou ao seu final quando ocorreu a saturação teórica, isto é, nenhum novo dado acrescentou novas nuances ao processo de análise e categorização. Dizemos, então, que a categoria central é a que recorre mais desde a primeira fase de codificação e é a que mais tempo leva para ser saturada (GOULDING, 2001).

Seguimos, nesse trabalho, as recomendações de Corbin e Strauss (1990) para a formatação da Teoria Substantiva que respondesse o seguinte problema: Quais as suas dificuldades na compreensão de assuntos de Genética?

Eis a Teoria Substantiva oriunda dos dados do entrevistado:

"A dificuldade de compreensão dos assuntos de Genética Molecular leva o aluno a uma interpretação incompleta dos fatos (fenômenos) em decorrência de uma percepção esporádica, não desenvolvendo assim atitudes reflexivas para o devido entendimento (entende, mas não interpreta) dos assuntos relacionados à Genética". 
A aprendizagem de genética à luz da Teoria Fundamentada: ...

\section{Considerações finais}

Refletindo sobre o Ensino de Genética, com a sustentação de teóricos que tratam dessa temática, percebe-se que ela é uma das áreas de difícil compreensão, devido à complexidade dos assuntos que por ela são abordados. Portanto, é imprescindível buscar alternativas, meios, estratégias e recursos didático-pedagógicos que possam cada vez mais facilitar o processo de ensino e aprendizagem dessa disciplina.

Diante de tal panorama, investigamos como uma Teoria Substantiva poderia ser construída a partir do seguinte problema científico: "Quais as suas dificuldades na compreensão de assuntos de Genética?"

Os métodos da Teoria Substantiva aqui discutidos basearam-se em diretrizes sistemáticas, ainda que flexíveis, para coletar e analisar os dados, visando a construção de Teorias Fundamentadas nos próprios dados. Dessa forma, os dados (que podemos chamar de indicadores) obtidos nesse trabalho (transcrições, códigos, subcategorias, categorias e categoria central) formaram a base para a construção de nossa Teoria.

Assim, ao mergulharmos na Teoria Fundamentada, começamos por estar abertos ao que ocorria durante todo o processo, de modo que pudéssemos entender sobre o fenômeno que ali se apresentava. Portanto, prestamos atenção àquilo que foi ouvido, falado e sentido durante a entrevista. Com o pensamento, a mente e o coração abertos, construímos os dados por meio de nossas observações, das interações e dos materiais sobre o objeto estudado.

Percebemos que foi um grande desafio aplicar o método da Teoria Fundamentada no ensino. Em virtude de ser, ainda, uma área pouco aplicada em estudos que envolvam a educação, sugerimos uma maior difusão da mesma e apropriação de sua epistemologia em trabalhos futuros.

\section{Referências}

BACELLAR, F. Contribuições para o ensino de marketing: revelando e compreendendo a perspectiva dos professores. 2005. 154 f. Tese (Doutorado) - Faculdade de Economia, Administração e Contabilidade, Universidade de São Paulo, São Paulo, 2005.

BAHAR, M.; JOHNSTONE, A. H.; HANSELL, M. H. Revisiting learning difficulties in biology. Journal of Biological Education, Philadelphia, v. 33, n. 2, p. 84-86, 1999. Disponível em: <http://dx.doi.org/10.1080/00219266.1999.9655648>. Acesso em: 9 dez. 2016.

BANET, E.; AYUSO, E. Introducción a la genética em la enseñanza secundaria y bachillerato: I. contenidos de la enseñanza y conocimientos de los alumnos. Enseñanza de las Ciencias, Barcelona, v. 13, n. 2, p. 137-153, 1995. Disponível em: < http://raco.cat/ index.php/Ensenanza/article/view/21403/93363>. Acesso em: 9 dez. 2016.

. Teaching of biological inheritance and evolution of living beings in secondary school. International Journal of Science Education, Abingdon, v. 25, n. 3, p. 373-407, 2003. Disponível em: <http://dx.doi.org/10.1080/09500690210145716>. Acesso em: 9 dez. 2016. 
Silva, C. C.; Kalhil, J. B.

BUGALLO RODRÍGUEZ, A. La didáctica de la genética: revisión bibliográfica.

Enseñanza de las Ciencias, Barcelona, v. 13, n. 3, p. 379-385, 1995. Disponível em: <http://www.raco.cat/index.php/Ensenanza/article/view/21426/93387>. Acesso em: 9 dez. 2016.

CHARMAZ, K. A construção da teoria fundamentada: guia prático para análise qualitativa. 2 ed. Porto Alegre: Artmed, 2009.

CORBIN, J.; STRAUSS, A. Basics of qualitative research. Thousand Oaks: Sage, 1990.

FRANCISCO, G. C. B. Ensino de genética: uma abordagem a partir dos estudos sociais de ciência e de tecnologia (ESCT). 2005. 120 f. Dissertação (Mestrado em Educação) Universidade Regional de Blumenau, Blumenau, 2005.

GASKELL, G. Pesquisa qualitativa com texto, imagem e som: um manual prático. 4. ed. Petrópolis: Vozes, 2002.

GIBBS, G. Análise de dados qualitativos. Porto Alegre: Artmed, 2009.

GLASER, B. G. Basics of grounded theory analysis. Mill Valley: Sociology Press, 1992. . Theoretical sensivity. Mill Valley: Sociology Press, 1978.

GLASER, B. G.; STRAUSS, A. L. Awareness of dying. Chicago: Aldine de Gruyter, 1965.

. The discovery of grounded theory: strategies for qualitative research. New York: Aldine de Gruyter, 1967.

. Time for dying. Chicago: Aldine, 1968.

GOULDING, C. Grounded theory: a magical formula or a potential nightmare. The Marketing Review, Helensburgh, v. 2, n. 1, p. 21- 33, 2001. Disponível em: < http://dx.doi. org/10.1362/1469347012569409>. Acesso em: 9 dez. 2016.

Grounded theory: a practical guide for management, business and market researchers. London: Sage, 2002.

GRIFFITHS, P. E. Genetic information: a metaphor in search of a theory. Philosophy of Science, Chicago, v. 68, n. 4, p. 394-403, 2001. Disponível em: <http://philsci-archive.pitt. edu/89/>. Acesso em: 9 dez. 2016.

HANNABUSS, S. Research interviews. New Library World, Bingley, v. 97, n. 5, p. 22-30, 1996. Disponível em: <http://dx.doi.org/10.1108/03074809610122881>. Acesso em: 9 dez. 2016.

HUTCHINSON, S. Education and grounded theory. In: SHERMAN, R. R.; WEBB, R. D. Qualitative research in education: focus and method. London: Falmer, 1988. p. 123-140.

KRASILCHIK, M. Prática de ensino de biologia. 4. ed. São Paulo: Edusp, 2004. 
LORETO, E. L. S.; SEPEL, L. M. N. Formação continuada de professores de biologia do ensino médio: atualização em genética e biologia molecular: programa de incentivo à formação continuada de professores do ensino médio. Santa Maria: Universidade Federal de Santa Maria: Departamento de Biologia, 2006. Disponível em: < http://portal.mec.gov.br/ seb/arquivos/pdf/formcont_ufsm.pdf >. Acesso em: 12 dez. 2016.

OMETTO-NASCIMENTO, T. A. et al. A evolução do ensino de genética no nível médio e a engenharia genética. In: CONGRESSO NACIONAL DE GENÉTICA, 47., 2001, Águas de Lindóia. Resumos... [S.1.]: Sociedade Brasileira de Genética, 2001. Disponível em: <http:// sites.netsite.com.br/sbgteste/PDF/47/1137.pdf>. Acesso em: 19 jan. 2014.

PACHECO, A. S. V. Evasão e permanência dos estudantes de um curso de administração do sistema Universidade Aberta do Brasil: uma teoria fundamentada em fatos e na gestão do conhecimento. 2010. 298 f. Tese (Doutorado em Engenharia e Gestão do Conhecimento) - Universidade Federal de Santa Catarina, Florianópolis, 2010.

PARANÁ. Secretaria de Estado da Educação. Diretrizes curriculares da educação básica: biologia. [Curitiba], 2008. Disponível em: <http://www.educadores.diaadia.pr.gov.br/ arquivos/File/diretrizes/dce_bio.pdf>. Acesso em: 9 dez. 2016.

Diretrizes curriculares da educação básica: ciências. [Curitiba], 2008. Disponível em: <http://www.educadores.diaadia.pr.gov.br/arquivos/File/diretrizes/dce_cien.pdf $>$. Acesso em: 9 dez. 2016.

PARTINGTON, D. Building grounded theories of management action. British Journal of Management, Chichester, v. 11, n. 3 p. 91-102, 2000. Disponível em: < https://dspace.lib. cranfield.ac.uk/bitstream/1826/959/3/Building_Grounded_Theories-2000.pdf>. Acesso em: 9 dez. 2016.

PARRY, W. Grounded theory and social process: a new direction for leadership research. Leadership Quarterly, Oxford, v. 9, n. 1, p. 85-106, 1998. Disponível em: < http://dx.doi. org/ 10.1016/S1048-9843(98)90043-1>. Acesso em: 9 dez. 2016.

SILVA, C. C. Análise sistêmica do processo ensino aprendizagem de genética à luz da teoria fundamentada. 2014. 186 f. Tese (Doutorado em Educação em Ensino de Ciências e Matemática) - Universidade Federal do Mato Grosso, Cuiabá, 2014.

STEWART, J. Dificulties experienced by high school students when learning basic endelian genetics. The American Biology Teacher, Oakland, v. 2, n. 44, p. 731-749, 1982.

STRAUSS, A. L. Qualitative analysis for social scientist. Cambridge: Cambridge University Press, 1987.

STRAUSS, A.; CORBIN, J. Basics of qualitative research: grounded theory procedures and techniques. 2. ed. Newbury Park: Sage, 1998.

TAROZZI, M. O que é a grounded theory: metodologia de pesquisa e de teoria fundamentada nos dados. Petrópolis: Vozes, 2011. 
TURCINELLI, S. R. et al. A transmissão do conhecimento científico da universidade para a sociedade. In: CONGRESSO NACIONAL DE GENÉTICA, 47., 2001, Águas de Lindóia. Resumos... [S.1.]: Sociedade Brasileira de Genética, 2001. Disponível em: <http:/ / sites. netsite.com.br/sbgteste/PDF/47/1107.pdf>. Acesso em: 19 jan. 2014.

VALLE, M. G. A. Argumentação na produção escrita de professores de ciências: implicações para o ensino de genética. 2009. 99 f. Dissertação (Mestrado em Educação) Universidade de São Paulo, São Paulo, 2009.

WOOD-ROBINSON, C. et al. Genética y formación científica: resultados de un proyecto de investigación y implicaciones sobre los programas escolares y la enseñanza. Enseñanza de las Ciencias, Barcelona, v. 1, n. 16, p. 43-61, 1998.

WOOD-ROBINSON, C.; LEWIS, J.; LEACH, J. Young people's understanding of the nature of genetic information in the cells of an organism. Journal of Biological Education, Philadelphia, v. 35, n. 1, p. 29-36, 2000.

XAVIER, M. C. F.; FREIRE, A. S.; MORAES, M. O. A nova (moderna) biologia e a genética nos livros didáticos de biologia no ensino médio. Ciência \& Educação, Bauru, v. 12, n. 3, p. 275-289, 2006. Disponível em: <http://dx.doi.org/10.1590/S1516-73132006000300003>. Acesso em: 9 dez. 2016. 